\title{
Avaliação do perfil e dos hábitos de aquisição de consumidores de produtos cárneos em Fortaleza - CE
}

\author{
Evaluation of the profile and purchasing habits of meat product consumers in Fortaleza - CE \\ Evaluación del perfil y hábitos de compra de los consumidores de productos cárnicos en Fortaleza -
}

CE

\section{Resumo}

Esse trabalho teve como objetivo identificar o perfil e compreender os hábitos dos consumidores de produtos cárneos da cidade de Fortaleza - CE. Através das redes sociais, aplicou-se questionário buscando compreender aspectos de consumo, qualidade e inspeção desses produtos. Verificou-se que 97,2\% dos entrevistados consumiam carnes e derivados, $70 \%$ pertenciam ao sexo feminino e maioria (46\%) com renda familiar entre 2 e 3 salários mínimos. As carnes com maior frequência de consumo foram frango $(63,2 \%)$ e bovina $(32,8 \%)$; carne suína $(2,5 \%)$ e pescado $(1,2 \%)$ apresentaram menor prevalência de consumo. Quanto ao local de compra de produtos cárneos, verificou-se a preferência por supermercados $(76,7 \%)$, o que pode ser atribuído aos consumidores acreditarem que este é um ambiente mais limpo e oferece um produto mais seguro ao consumo. Ao correlacionar renda com escolha do produto, observou-se que independentemente do valor da renda familiar, qualidade é mais relevante do que preço, indicando que implementar métodos de segurança alimentar nos pontos de venda pode ser considerado investimento para conquista de clientes. As medidas de melhoria sugeridas pelos participantes abrangeram reforma dos locais, atividades de capacitação para os comerciantes e aplicação de estratégias de fiscalização mais eficazes. Assim, constatou-se que os consumidores do município de Fortaleza relacionam possíveis riscos à saúde com a compra de produtos cárneos sem inspeção ou sem procedência de origem. Além disso, condições das instalações e higiene do estabelecimento, também são considerados fatores determinantes para a decisão sobre escolha do local de compra de produtos cárneos.

Palavras-chave: Consumidores; Produtos cárneos; Educação para promoção à saúde.

\begin{abstract}
This work aimed to identify the profile and understand the habits of consumers of meat products in the city of Fortaleza - CE. Through social networks, a questionnaire was applied seeking to understand aspects of consumption, quality and inspection of these products. It was found that $97.2 \%$ of respondents consumed meat and meat products, $70 \%$ were female and the majority (46\%) with family income between 2 and 3 minimum wages. The meats with the highest consumption frequency were chicken $(63.2 \%)$ and beef $(32.8 \%)$; pork meat $(2.5 \%)$ and fish $(1.2 \%)$ had a lower prevalence of consumption. As for the place of purchase of meat products, there was a preference for supermarkets (76.7\%), which can be attributed to consumers believing that this is a cleaner environment and offers a safer product for consumption. When correlating income with product choice, it was observed that, regardless of the value of family income, quality is more relevant than price, indicating that implementing food safety methods at points of sale can be considered an investment in attracting customers. Improvement measures suggested by participants included renovating the sites, training activities for traders and applying more effective enforcement strategies. Thus, it was found that consumers in the city of Fortaleza relate possible health risks to the purchase of meat products without inspection or
\end{abstract}


origin. In addition, the conditions of the premises and hygiene of the establishment are also considered determining factors for the decision on choosing the place to buy meat products.

Keywords: Consumers; Meat products; Health promotion education.

\section{Resumen}

Este trabajo tuvo como objetivo identificar el perfil y comprender los hábitos de los consumidores de productos cárnicos en la ciudad de Fortaleza - CE. A través de las redes sociales se aplicó un cuestionario que busca comprender aspectos de consumo, calidad e inspección de estos productos. Se encontró que el 97,2\% de los encuestados consumían carne y productos cárnicos, el $70 \%$ eran mujeres y la mayoría (46\%) con ingresos familiares entre 2 y 3 salarios mínimos. Las carnes con mayor frecuencia de consumo fueron el pollo $(63,2 \%)$ y la ternera $(32,8 \%)$; la carne de cerdo $(2,5 \%)$ y el pescado $(1,2 \%)$ tuvieron una menor prevalencia de consumo. En cuanto al lugar de compra de los productos cárnicos, hubo preferencia por los supermercados $(76,7 \%)$, lo que se puede atribuir a que los consumidores creen que se trata de un ambiente más limpio y ofrece un producto más seguro para el consumo. Al correlacionar los ingresos con la elección de productos, se observó que, independientemente del valor de los ingresos familiares, la calidad es más relevante que el precio, lo que indica que implementar métodos de inocuidad alimentaria en los puntos de venta puede considerarse una inversión en la captación de clientes. Las medidas de mejora sugeridas por los participantes incluyeron la renovación de los sitios, actividades de capacitación para comerciantes y la aplicación de estrategias de cumplimiento más efectivas. Así, se encontró que los consumidores de la ciudad de Fortaleza relacionan posibles riesgos para la salud con la compra de productos cárnicos sin inspección ni origen. Además, las condiciones del local y la higiene del establecimiento también se consideran factores determinantes para la decisión de elegir el lugar para comprar productos cárnicos.

Palabras clave: Consumidores; Productos de carne; Educación para la promoción de la salud.

\section{Introdução}

Produtos considerados fontes de proteínas, de alto valor biológico e rico em vitaminas e minerais de alta biodisponibilidade como o zinco e ferro, os produtos cárneos além de apresentarem concentração de ácidos graxos significativas, ainda apresentam benefícios à saúde para quem consome (Hooper, 2006; Sidhu, 2003).

Devido a sua composição rica em nutrientes e por apresentar alta atividade de água, os produtos cárneos podem sofrer rápida deterioração, além de alterações ocasionadas pelas próprias enzimas e pela atividade microbiana (Fanalli, 2018). Os alimentos podem ser suscetíveis à contaminação em todas as etapas de sua produção, transporte e armazenamento. Quando em condições de comercialização inadequadas, podem se tornar vias de transmissão de doenças alimentares.

Dessa forma, se torna indispensável a observação, no momento da compra, de alguns aspectos essenciais relacionados ao produto e ao estabelecimento, pois, em conjunto garantem a sua qualidade. É importante observar a higiene do estabelecimento comercial, balcões frigoríficos e funcionários, as condições de temperatura em que estes produtos são mantidos e suas características sensoriais, além de informações apresentadas no rótulo do produto, como prazo de validade, temperatura de conservação, dentre outras (Conceição, 2009).

Os consumidores têm se tornado uma fonte de estudos por serem uma parte principal na cadeia de produção de alimentos. Entretanto, estes possuem pouca informação a respeito dos sistemas produtivos da carne e seus aspectos de qualidade e ainda permanecem utilizando como guias de escolha seus hábitos e tradições, sem conhecimento suficiente para realizar julgamentos sobre a qualidade sanitária dos produtos. Diante do exposto, esse trabalho teve como objetivo identificar o perfil e compreender os hábitos de aquisição de consumidores de produtos cárneos em Fortaleza - CE.

\section{Metodologia}

A população da pesquisa foi delimitada por homens e mulheres, a partir dos 18 anos de idade, residentes na cidade de Fortaleza-CE, e considerados consumidores de produtos cárneos. O tipo de amostragem utilizado será o cálculo do tamanho da amostra da pesquisa através do programa SurveyMonkey Audience. A coleta de dados foi realizada nos meses de agosto e setembro de 2020, de forma aleatória por questionários distribuídos via redes sociais. 
Os participantes receberam um questionário eletrônico alocado na plataforma Google Forms pelas mídias sociais como Instagram, WhatsApp, e-mail e Facebook. As instruções de preenchimento do teste e ficha eletrônica constavam no formulário Google Forms. O tempo de duração da pesquisa para cada participante foi o necessário para adquirir as respostas. Vinte e duas perguntas relacionadas ao sexo, faixa etária, escolaridade, renda familiar, qualidade microbiológica, inspeção e consumo de produtos cárneos foram aplicadas.

\section{Resultados e Discussão}

Entre os 335 participantes, 97,2\% possuíam o hábito de consumir produtos de origem animal, tais como as carnes bovina, suína, caprina, de aves e pescado. A maioria $(73,1 \%)$ dos entrevistados residia em Fortaleza, seguido pela região metropolitana $(20,0 \%)$ e outros locais $(6,9 \%)$.

Em relação ao gênero dos avaliados $70 \%$ pertencia ao sexo feminino e $30 \%$ ao masculino. O mesmo resultado foi encontrado em outros estudos de perfil de consumidores por Pessoa et al (2020), de Lima et al (2020).

A faixa etária dos consumidores estava entre os 21 e 40 anos (83,6\%); o remanescente estava dividido entre 41 e 60 $\operatorname{anos}(9,3 \%), 18$ e $20 \operatorname{anos}(6,6 \%)$ e acima de 60 anos (0,6\%), o que demonstra que a maioria dos indivíduos estão em plena idade laborativa e tendem a ser mais práticos em relação a escolha dos alimentos, talvez por terem pouco tempo disponível para os serviços domésticos (Silva Júnior, 2018; Pinto, 2020). Em estudo realizado por Alves et al (2014), foi observado que o conhecimento do perfil do cliente é relevante, visto que, o pensamento de aquisição de produtos/alimentos se modificou e já não basta saber o que e como produzir, mas também para quem produzir.

Em relação à escolaridade, constatou-se uma maior participação de pessoas com ensino superior incompleto (45,1\%), seguido por aqueles que tinham pós graduação (26,3\%), ensino superior $(21,2 \%)$ e ensino médio e fundamental que, juntos, contemplaram 7,5\% dos participantes da pesquisa. Esses dados são relevantes, para que se possa relacionar o nível de alfabetização com os critérios e importância dada ao processo de compra dos produtos.

Na classificação dos entrevistados quanto à renda mensal média dos consumidores, pôde-se observar que 63\% relataram ter rendimentos entre 1-3 salários-mínimos; 18,2\% entre 3-6 salários mínimos; 12,2\% entre 6 a 10 salários mínimos e somente 6,6\% relatou ter renda acima de 10 salários mínimos. Esse aspecto possui grande importância, pois pode apontar para o varejo em quais regiões o seu produto será mais procurado (Pinto, 2020).

O grau de escolaridade associado à renda familiar pode influenciar na aquisição de produtos cárneos, visto que pessoas com maior nível de escolaridade e maior poder aquisitivo possuem mais informações sobre os alimentos que consome, sabendo identificar notícias verídicas, sugerindo um interesse maior pelo cuidado com a saúde através da alimentação. Além disso, a renda familiar pode estimular o consumo de alguns produtos cárneos, como também, o valor despendido por quilograma de carne adquirida (Kirinus et al., 2013; Raimundo, 2009).

A maioria dos entrevistados $(83,4 \%)$ afirmou consumir produtos cárneos diariamente, enquanto o consumo semanal ficou em torno de $16,0 \%$ e quinzenal 0,6\%. A carne com maior frequência de consumo foi o frango (63,2\%), seguida pela bovina $(32,8 \%)$ e suína $(2,5 \%)$, com menor prevalência de consumo para pescado (1,2\%) (Figura 1). 
Figura 1 - Percentual de consumo de carnes em Fortaleza (CE).

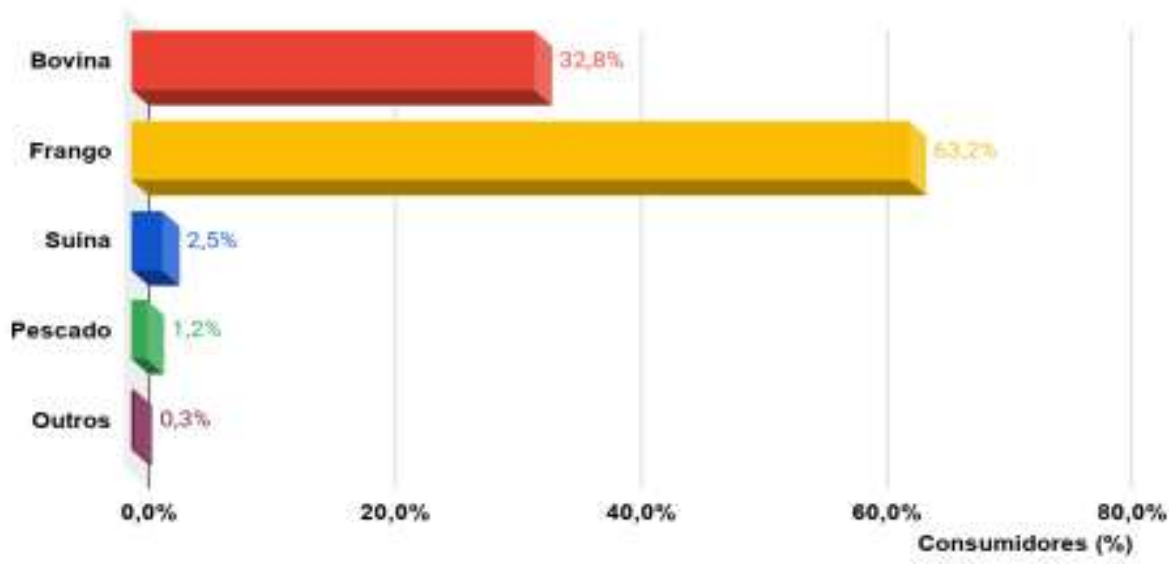

Fonte: Autores (2020).

O alto consumo da carne de frango pode ser explicado pelo forte apelo nutricional dado pela mídia e pelo fato de o custo ser menor em relação aos outros tipos de carne, o que torna mais acessível para consumo diário. Em uma pesquisa realizada sobre o consumo de carnes em Alto Pantanal (MS) por Nascimento et al. (2018), foi constatado que o valor mais baixo da carne de frango em relação à carne bovina é o que impulsiona o seu consumo para $37 \%$ dos entrevistados, assim como o fato de ser considerada saudável por 10\% dos consumidores. Na mesma pesquisa, Nascimento et al (2018) observaram que seus resultados diferiram dos obtidos pelos estudos realizados por Oliveira et al (2017) e Albuquerque et al. (2017), que observaram maior preferência de consumo para carne bovina, seguida da carne de aves e suína.

Outro trabalho que confirma a relação do menor custo desse tipo de carne foi demonstrado por Pinto (2020) que observou que a carne de frango foi a mais consumida, com 50\% das respostas dos participantes, e os motivos atribuídos a esse consumo foram a preferência com $38 \%$, seguida de sabor com $20 \%$, preço com $16 \%$, hábito com $13 \%$, valor nutritivo com $10 \%$, praticidade com $4 \%$.

O baixo consumo de pescado pode ser diminuído com ações efetivas que promovam a diminuição do custo e divulguem informações sobre seus benefícios. Figueira (2015) confirma isso com a observação de uma semana dedicada ao pescado em Belém (PA) que gerou um impacto positivo na compra, utilizando estratégia de redução no preço do peixe como incentivo ao consumo e por consequência o aumento da comercialização. Pinto et al (2020) observaram que $22 \%$ dos seus entrevistados optam por adquirir peixes na forma de congelados, $21 \%$ na forma de posta, $18 \%$ optaram pelo filé e apenas $7 \%$ na forma in natura; isso infere que apresentações mais fáceis de preparo e consumo do pescado podem ser um fator que influencia no momento de compra.

O baixo consumo de outras carnes, como a ovina, por exemplo, pode ser explicada pela pouca oferta em supermercados ou comércio, quando comparado a outros tipos. Além disso, a falta de hábito em relação ao consumo (57,97\%), baixa disponibilidade $(20,28 \%)$ e a apresentação dessas carnes no varejo, quase sempre em peças com osso, dificultam sua aquisição e preparação (Alves et al., 2017). Rosanova et al (2021) observaram um ponto interessante quando compararam a aceitação entre gêneros, que a maior preferência por um produto não representa necessariamente em um maior consumo deste em relação a outros, pois em seu trabalho o público masculino mostrou maior aceitação ao produto carne suína com 90,9\% em detrimento ao público feminino, 77,02\%, e no geral dos participantes obteve predileção por carne bovina com 52\%.

Quanto ao local de compra de produtos cárneos, verificou-se a preferência da compra em supermercados $(76,7 \%)$ e frigoríficos (16,3\%), sendo seguido pela compra efetuada em mercearias (3,7\%), o que aponta que os consumidores preferem a praticidade e forma de comercialização oferecida pelos supermercados a locais como mercearias, mercados municipais, feiras livres. Ambientes públicos como feiras e mercados são locais que comercializam diversos produtos in natura e por fatores como 
estrutura, armazenamento e manipulação podem reduzir a qualidade dos produtos ofertados. Em uma avaliação das condições higiênico-sanitárias e microbiológicas de 08 pontos de venda em feiras livres de um município do sertão nordestino, Pereira et al (2020) concluíram que as carnes comercializadas eram impróprias para o consumo por conter alto índice de contaminação. Albuquerque et al (2017) observaram que os consumidores estão buscando por alimentos com qualidade, certificações e que atestem a existência de atributos de qualidade nos alimentos adquiridos; o que influencia na decisão e local de compra e confirma os resultados encontrados neste trabalho.

A forma de preparo dos produtos cárneos preferida pelos consumidores, foi cozido $(36,5 \%)$, frito $(31,3 \%)$ e assado $(27,9 \%)$ sendo empanado e as outras formas menos consumidas.

Cerca de 257 consumidores fizeram correlação entre o consumo de produtos cárneos mal cozidos ou crus com a ocorrência de doenças intestinais, enquanto que 31 afirmaram não ter correlação e 38 apresentaram dúvida. Os participantes que associam a doenças intestinais justificaram sua resposta por afirmarem ter a permanência de microrganismos nocivos nos alimentos pela falta de cozimento ou cozimento incorreto. Dentre os consumidores que apresentaram dúvidas, justificaram que só relacionavam os produtos cárneos a doenças alimentares quando sentiam algum problema de saúde.

O hábito de lavar carnes foi confirmado pela maioria dos respondentes $(54,6 \%)$, o que torna evidente a carência de informações sobre o risco a saúde que esse hábito representa devido a contaminação cruzada causada por espalhar possíveis microrganismos contidos no alimento cru para superfícies e utensílios, assim como a perda de compostos que são solúveis em água e durante esse processo são retirados dos produtos cárneos.

Esse hábito comum entre os participantes reforça a necessidade de práticas públicas que abordem as boas práticas de manipulação de alimentos desde casa para corrigir essas atividades que aumentam o risco de doenças transmitidas por alimentos (dtas).

A qualidade e frescor do produto cárneo foi o item mais apontado como critério de escolha da compra do produto cárneo (46,6\%), seguido pela confiança no local de venda (21,5\%), enquanto os fatores preço e proximidade da residência foram menos significativos (Figura 2).

Figura 2 - Critérios de escolha do local de compra de produtos cárneos em Fortaleza (CE).

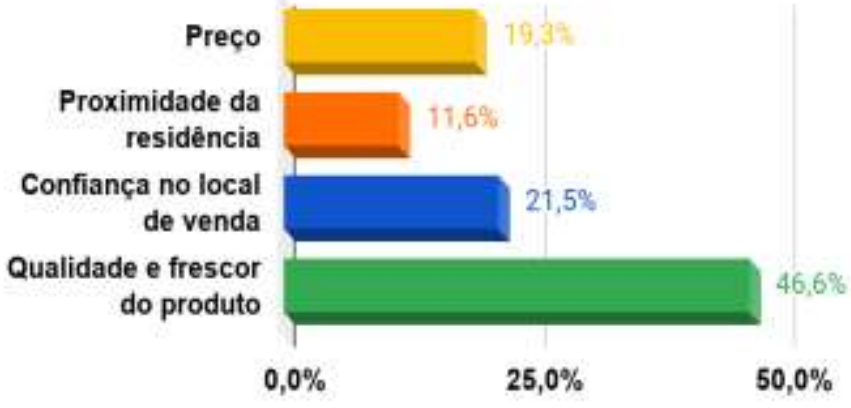

Fonte: Autores (2020).

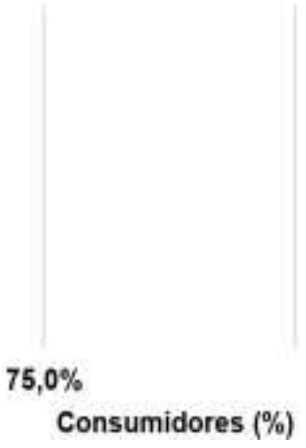

Consumidores (\%)

Ao relacionar a renda familiar e a escolha do produto, percebe-se que independentemente do valor de renda dos entrevistados, a qualidade do produto é mais relevante do que o preço, o que indica que a implementação de métodos que garantam a qualidade do alimento nos pontos de venda são uma forma de atrair clientes e um investimento para os setores da cadeia produtiva. Sousa et al (2020) também chegou ao mesmo resultado e afirma que as indústrias de carnes precisam criar táticas de disponibilização nos pontos de venda e de apresentação dos seus produtos.

A maioria dos consumidores $(92,6 \%)$, afirmou levar em consideração a higiene do local para aquisição de produtos cárneos, assim como, 91,4\% observam as condições de comercialização dos produtos como a temperatura de exposição, cor da 
carne, presença de moscas e/ou outros insetos sobre a superfície da carne, animais de estimação, pássaros, lixo acumulado e infraestrutura. O que mais uma vez, reitera que a implementação de cuidados com a higienização e boas práticas no ponto de venda é um atrativo comercial.

Ao serem questionados em relação a temperatura de comercialização e aquisição das carnes, 67,5\% afirmaram que adquirem carnes que são comercializadas sob refrigeração e 26,1\% sob congelamento. As temperaturas utilizadas no armazenamento durante a comercialização dos alimentos auxiliam na inibição do desenvolvimento de microrganismos e a faixa entre $0^{\circ} \mathrm{C}$ e $7^{\circ} \mathrm{C}$ são consideradas adequadas para a comercialização carnes bovinas, suínas e ovinas de acordo com a Portaria ${ }^{\circ}$ 304/96/MAPA (BRASIL, 1996).

Apenas 6,4\% (21) responderam adquirir carnes comercializadas a temperatura ambiente, o que representa um risco à saúde por serem produtos muito suscetíveis a deterioração nessa condição. Borges (2019) constatou que as carnes, quando comercializadas em temperaturas inadequadas, podem não apresentar mudanças de cor e aroma que sejam perceptíveis, o que pode propiciar ao consumidor a impressão de produto sem perda de qualidade, visto que, temperaturas acima do permitido podem propiciar desenvolvimento bacteriano causando danos à saúde.

A maioria $(60,4 \%)$ dos consumidores consultados afirmou não procurar saber a origem dos produtos cárneos que adquirem ou não se informam se o produto tem o selo de inspeção ou nunca tiveram interesse por essa informação, enquanto, apenas 39,6\% (129) procuram saber a origem.

Um resultado semelhante foram encontrados por Rosanova et al (2021), com maioria (78\%) dos participantes admitindo não observar durante a compra a verificação da inspeção federal da carne e por Fanalli (2018) em aplicação de questionário, na cidade de Uberlândia (MG), notou que 30\% dos entrevistados alegaram não saber identificar um produto de qualidade e inspecionado, o restante (70\%) responderam que quando o produto possui selo S.I.F. significa ter sido inspecionado, e desses, 12,28\% assumiram não saber o significado da sigla. Esses dados demonstram a carência de informações dos consumidores sobre como ocorre o processo de controle e inspeção dos produtos cárneos e como identificá-los em um alimento, o que torna a cobrança do cliente por produtos que tenham essas características mais improvável. Contudo, notou-se que 98,5\% (321) dos consumidores acreditam que os produtos cárneos não inspecionados ou sem procedência de origem, após serem ingeridos, podem ocasionar algum dano à saúde.

Ao serem questionados se já tinham ouvido falar sobre doenças transmitidas por alimentos ou terem sido acometidos por alguma, apenas 12,8\% (43) não tinham ouvido falar. Esse resultado demonstra que o consumidor está mais consciente dos problemas de saúde relacionados a alimentos e, que pode estar diretamente ligado ao consumo em locais com melhores cuidados com as carnes.

As doenças mais citadas foram salmonelose, cisticercose, botulismo e verminoses, além de infecções alimentares e bactérias como agentes causadores. Fanalli (2018) obteve resultado semelhante em que 61,84\% dos entrevistados citaram doenças bacterianas no geral, além de verminoses.

As respostas ainda citavam a carne suína como fonte de doenças alimentares, o que pode ser justificado pela possível ideia de que os processos de criação e abate desses animais não são higiênicos. Pois, circulam nos diversos meios de comunicação informações errôneas que não auxiliam no controle de doenças (Fanalli, 2018).

O uso de imagens de ambientes reais da cidade de Fortaleza (CE) foi utilizado como uma maneira de captar a atenção dos participantes durante a realização dos questionários, além de demonstrar os aspectos de higiene e manipulação dos produtos cárneos. As falhas presentes nos ambientes demonstrados nas imagens foram percebidas e apontadas pelos entrevistados. Sobre o impacto que as condições de comercialização que esses ambientes poderiam trazer à saúde dos consumidores e para a saúde pública, as respostas se resumiram a relacionar os produtos comercializados nas imagens a doenças (96,2\%). 
Enquanto que, as medidas de promoção à saúde sugeridas aos responsáveis por esses locais variaram de higienização dos locais $(22,7 \%)$, controle de temperatura $(22,1 \%)$, treinamento dos comerciantes $(3,6 \%)$ e troca da estrutura física $(7,2 \%)$, entre outros. Parte das respostas $(4,5 \%)$ obtidas ainda mencionaram o acionamento da fiscalização sanitária como forma de acompanhamento das condições de venda e solução da situação, medidas essas que são praticáveis e que reduziriam os perigos encontrados nos ambientes públicos de comercialização de cárneos.

\section{Conclusão}

Os consumidores de Fortaleza relacionam os riscos de saúde à compra de produtos sem inspeção ou sem procedência de origem. A escolha do local de compra é influenciada pela aparência e higiene do estabelecimento. As medidas de promoção sugeridas pelos participantes englobaram a reforma dos locais assim como a aplicação de atividades de capacitação e informação dos comerciantes, além de fiscalização mais eficaz com registro de multas aos locais não conformes.

Ações educativas sobre boas práticas de manipulação e melhorias da infraestrutura desses ambientes públicos que manipulam produtos cárneos são sugeridas e consideradas itens de alta importância para que se tenha a conscientização e resultados positivos na diminuição dos perigos existentes.

A elaboração e uso de cartilhas, palestras e cursos voltados para os permissionários são medidas que podem ser preparadas em parceria com as organizações governamentais responsáveis por esses ambientes junto com universidades locais desenvolvendo assim, projetos que beneficiam toda a população e trazem um maior fluxo de informações corretas sobre a manipulação e comercialização de produtos cárneos.

\section{Referências}

Albuquerque, I. D., Gois, G. C., Campos, F. S., Silva, T. S. \& Matias, A. D. S. (2017). Pesquisa de mercado: Hábitos de compra e consumo de carne em Senhor do Bonfim-Bahia. Revista Eletrônica Nutritime, 14, 5024-209. https://www.nutritime.com.br/arquivos_internos/artigos/Artigo_418.pdf.

Alves, L. G. C., da Cunha, C. M., Fernandes, A. R. M., de Vargas Junior, F. M., Hirata, A. S. O., da Silva Paes, M. R., ... \& da Silveira Osório, J. C. (2017). Perfil do consumidor de carne ovina na cidade de Dourados-MS. Agrarian, 10(37), 289-93. https://ojs.ufgd.edu.br/index.php/agrarian/article/view/6671.

Alves, L. G., Osório, J. C., Fernandes, A. R., Ricardo, H., \& Cunha, C. (2014). Produção de carne ovina com foco no consumidor. Enciclopédia Biosfera, 10(18). Borges, A. C. C., \& de Oliveira Souza, S. M. (2019). Controle de temperatura: importância e influência na qualidade da carne bovina. PUBVET, 13 , 158.

BRASIL. (1996). Portaria $\mathrm{n}^{\mathrm{o}} 304$, de 22 de abril de 1996. Ministério da Agricultura, Pecuária e Abastecimento. http://www.cidasc.sc.gov.br/inspecao/files/2020/06/03.-Portaria-304.1996-MAPA-Orienta\%C3\%A7\%C3\%B5es-temperatura-carne-bovina.pdf.

Conceição, F. V. E, Gonçalves, E. C. B. A. (2009) Qualidade físicoquímica de mortadelas e carnes moídas e conhecimento dos consumidores na conservação destes produtos. Ciência Tecnologia Alimentar. 29(2):283-90.

De Lima, A. M., de Oliveira Melo, W., Albuquerque, G. D. P., do Nascimento, J. B., \& Cândido, E. P. (2020). Mercado consumidor de carne de frango e derivados em Capanema, Pará. Brazilian Journal of Development, 6(5), 26810-26824. https://www.brazilianjournals.com/index.php/BRJD/article/view/9908.

Fanalli, S. L. (2018). Perfil de consumo e percepção dos consumidores de carne: consequências sobre a saúde pública. Revista Científica de Medicina Veterinária, 31 .

Figueira, Y. L. V. (2015). Perfil de consumidores de pescados em supermercados na semana do peixe em Belém/PA. Nutrição Brasil, 14(4).

Hooper L, Thompson RL, Harrison RA, Summerbell CD, Ness A.R, Moore, H.J, Worthington, H.V, Durrington, P.N, Higgins, J.P, Capps, N.E, Riemersma, R.A, Ebrahim, S.B \& Davey Smith, G. (2006). Risks and benefits of omega 3 fats for mortality, cardiovascular disease, and cancer: Systematic Review. bmj. 332(7544):752-760. https://pubmed.ncbi.nlm.nih.gov/16565093/.

Kirinus, J. K., Fruet, A. P. B., Klinger, A. C. K., Dörr, A. C., \& Nörnberg, J. L. (2013). Relação entre faixas de renda e o perfil dos consumidores de carne bovina da região sul do Brasil. Revista Monografias Ambientais, 12(12), 2776-2784. https://www.brazilianjournals.com/index.php/BRJD/article/view/16059.

Nascimento, J. D., Oliveira, D. M., Rocha, T. O. F., Rohod, R. V., Piazzon, C. J., \& Escobar, L. S. (2018). Perfil do consumidor de carnes do Alto Pantanal sulmato-grossense. Revista Acadêmica: Ciência Animal, Curitiba, 16, 1-9.

Oliveira, A. P., da Silva, C. P., Júnior, H. A. D. S., dos Santos, M. S., de Brito, J. M., Mendes, F. B. L., \& Santana, E. O. C. (2017). Principais aspectos considerados por consumidores na aquisição e consumo de carne suína em Colônia do Piauí-PI. Arquivos de Ciências Veterinárias e Zoologia da UNIPAR, 20(2). 
Pereira, H. G. de S., Souza, E. N. de., \& Silva, C. de S. (2020). Qualidade sanitária da carne caprina comercializada em feiras de uma cidade do sertão nordestino. Research, Society and Development, 9 (11), e8109119714. https://doi.org/10.33448/rsd-v9i11.9714.

Pessoa, R. M. dos S., Costa, D. C. da C. C., Ferreira da Silva, A. A., Araújo, C. de A., \& Gois, G. C. (2020). Caracterização do consumidor de carne de frango e de ovos de aves de granja pela população do município de Olho d'Água/PB, Brasil. Diversitas Journal, 5(3), 2152-2164. https://doi.org/10.17648/diversitasjournal-v5i3-1053.

Pinto, M. L. B. (2019). Perfil do consumidor de peixe na microrregião do Brejo Paraibano. Trabalho de conclusão de curso. https://repositorio.ufpb.br/jspui/bitstream/123456789/17733/1/MLBP29062020-MZ328.pdf.

Raimundo, L. M., \& DE ZEN, S. de (2010) Aferição do perfil do consumidor de carne suína-Estudo de caso Carrefour/Jundiaí (SP). In Tecnologias, desenvolvimento e integração social; anais. Brasília: SOBER. https://repositorio.usp.br/item/002126321.

Rosanova, C., Rebouças, G. F., Camargos, D. M. L., Ismar, M. G., dos Santos Marinho, W. A., da Silva, M. D. M. P., \& de Freitas, P. V. D. X. (2021). Processo decisório de compra e caracterização do consumidor de carne suína na cidade de Palmas-TO. Extensão Rural: Práticas e Pesquisas Para o Fortalecimento da Agricultura Familiar - Volume 1. $\quad$ p.535-546. https://www.researchgate.net/publication/348862716_Processo_decisorio_de_compra_e_caracterizacao_do_consumidor_de_carne_suina_na_cidade_de_palm as-_to.

Sidhu, K. S. (2003). Health benefits and potential risks related to consumption of fish or fish oil. Regul Toxicol Pharmacol. 38(3):336-344. https://pubmed.ncbi.nlm.nih.gov/14623484/.

Silva júnior, M.G., Cardoso, C. F. (2018). As barreiras encontradas por pessoas da terceira idade no mercado de trabalho. Trabalho de conclusão de curso. Faculdade Evangélica de Jaraguá. http://repositorio.aee.edu.br/jspui/handle/aee/1007.

Sousa, L. K. S. D., Roque-Specht, V. F., \& Gomes, E. M. D. C. (2020). Principais Direcionadores de Compra de Carnes em Hipermercados. Revista de Administração Contemporânea, 24, 335-348. https://www.scielo.br/j/rac/a/nFBT3MYhzjqSyR833dxJT4G/?lang=pt. 